\title{
Influências das teorias de aprendizagem nas propostas curriculares de Matemática Pós-70: continuidade e ruptura
}

\author{
José Carlos Miguel ${ }^{1}$
}

\begin{abstract}
RESUMO
O presente artigo analisa a influência das teorias de aprendizagem na constituição das propostas curriculares para o ensino de Matemática do período pós-70 no estado de São Paulo e como essas tentativas de renovação dos programas de ensino compreendem o processo de difusão do conhecimento matemático, com ênfase na perspectiva teórica adotada. Partindo de pesquisa bibliográfica, analiso documentos curriculares do estado de São Paulo, além dos Parâmetros Curriculares Nacionais e da Base Nacional Comum Curricular, BNCC. Os resultados indicam que se trata de programas cujos fundamentos transitam da concepção de aprendizagem por associação de modelos, passa pela abordagem cognitivista de diversos matizes e, ainda que de forma incipiente, aponta para constructos teóricos relacionados à aprendizagem verbal significativa. Observa-se a descontinuidade das propostas de renovação dos programas de ensino e desconsideração das teses das reformas curriculares pelos professores, principalmente nos aspectos que exigem reflexão conceitual sobre o processo de ensino.
\end{abstract}

PALAVRAS-CHAVE: Educação Matemática. Teorias de Aprendizagem. Propostas Curriculares. Cultura Escolar. Teoria Histórico-Cultural.

\section{Influences of learning theories on post-70 mathematics curriculum proposals: continuity and break}

\footnotetext{
${ }^{1}$ Livre-Docente em Educação Matemática. Professor Associado vinculado ao Departamento de Didática e ao Programa de Pós-Graduação em Educação da UNESP, Câmpus de Marília, SP, Brasil. http://orcid.org/0000-0001-9660-3612. jocarmi@terra.com.br.
} 


\begin{abstract}
This article analyzes the influence of learning theories on the constitution of curricular proposals for post-70 Mathematics teaching in the state of São Paulo and how these attempts to renew teaching programs process of spreading mathematical knowledge, with emphasis on the adopted theoretical perspective. Starting from bibliographic research, I analyze curricular documents from the state of São Paulo, in addition to the National Curriculum Parameters and the Common National Curricular Base, BNCC. The results indicate that these are programs whose foundations move from the conception of learning by association of models, goes through the cognitivist approach of several shades and, although in an incipient way, points to theoretical constructs related to meaningful verbal learning. It is observed the discontinuity of the proposals of renewal of the teaching programs and disregard of the theses of the curricular reforms by teachers, mainly in aspects that demand conceptual reflection on the teaching process.
\end{abstract}

KEYWORDS: Mathematical Education. Learning Theories. Curriculum Proposals. School Culture. Historical-Cultural Theory.

\title{
Influencias de las teorías de aprendizaje en las propuestas de currículo de matematicas post-70: continuidad y descanso
}

\section{RESUMEN}

Este artículo analiza la influencia de las teorías del aprendizaje en la constitución de propuestas curriculares para la enseñanza de Matemáticas post-70 en el estado de São Paulo y cómo estos intentos de renovar los programas de enseñanza comprenden el proceso de difusión del conocimiento matemático, con énfasis en la perspectiva teórica adoptada. Con base en investigación bibliográfica, analizo documentos curriculares del estado de São Paulo, además de los Parámetros Curriculares Nacionales y la Base Curricular Común Nacional, BNCC. Los resultados indican que se trata de programas cuyos fundamentos se mueven desde la concepción del aprendizaje por asociación de modelos, pasan por el enfoque cognitivode diferentestonos $\mathrm{y}$, aunque de forma incipiente, apuntan a construcciones teóricas relacionadas con el aprendizaje verbal significativo. Se observa la discontinuidad de las propuestas de renovación de los programas de enseñanza y el desprecio de las tesis de las reformas 
curriculares por parte de los docentes, principalmente en aspectos que requieren una reflexión conceptual sobre el proceso de enseñanza.

PALABRAS CLAVE: Educación Matemática. Teorías de Aprendizaje. Propuestas Curriculares. Cultura Escolar. Teoría Histórico-Cultural.

$* * *$

\section{Introdução}

Consolidaram-se nas últimas décadas importantes produções científicas no contexto das relações entre Psicologia e Educação Matemática (Schliemann et al., 2003; Brito, 2001) voltadas à fundamentação teórica do movimento e situadas, em geral, na busca de compreensão de como as crianças se apropriam dos conceitos matemáticos, como os sujeitos pensam logicamente ou como os professores podem ensiná-los, consolidando-se as preocupações sobre o desenvolvimento cognitivo individual, ou seja, sobre o processo de aprendizagem de princípios e conceitos matemáticos.

Nesse período histórico, as preocupações com a renovação dos programas de ensino de Matemática, e dos currículos, de forma geral, situamse principalmente no contexto do processo de redemocratização da sociedade brasileira, impondo além da necessidade de ampliação do alcance do direito à educação, uma série de reformas estruturais voltadas à reorganização curricular com vistas à democratização do ensino. Mais do que vagas, o movimento exige tentativas de renovação dos programas de ensino no sentido de favorecer a aprendizagem da maioria dos alunos.

Em síntese, a pressão demográfica, somada à expansão da demanda em decorrência da crescente urbanização e à ampliação do acesso à escolaridade obrigatória, traz para a escola uma clientela cuja principal característica é a heterogeneidade com a qual a ação escolar cotidiana não sabe lidar com eficácia a se considerar os indicadores de avaliação em grande escala, atualmente em voga. No caso da Matemática, os resultados são preocupantes, 
apesar dos esforços das equipes técnico-pedagógicas institucionais para o seu enfrentamento.

De forma geral, as tentativas de explicação das dificuldades com a aprendizagem da Matemática na escola elementar transitam pelas ideias de condições inadequadas de trabalho, formação inadequada do professor (Brum, 2013), problemas de assimilação dos alunos (Brito, 2011), obsolescência do material didático (Imenes, 1989), inadequação de programas de ensino, concepções e representações de alunos e professores sobre o que é a Matemática (Passos \& Nacarato, 2018), entre outras.

Por certo, cada aspecto dessa problemática merece consideração e cumpre um papel no desempenho dos alunos em todos os níveis de ensino. Sob o nosso ponto de vista, no entanto, entre tais invariantes, as dificuldades de aprendizagem matemática revelam uma marca distintiva que se mostra de difícil superação ao longo dos anos porque é fortemente enraizada na dinâmica de trabalho escolar, apesar dos esforços para a superação em diversas tentativas de renovação dos programas de ensino de Matemática: a conduta pedagógica face ao aluno na escola praticamente não muda, embora o perfil da clientela seja muito diferente.

Parece-me indiscutível que a evolução histórica do processo de fundamentação teórica da construção curricular na realidade brasileira se estabelece nos limites do paradigma curricular técnico-linear que sustenta uma cultura escolar cuja compreensão do processo de ensino ainda se situa no contexto da memorização imitativo-repetitiva de procedimentos algorítmicos quase sempre incompreendidos pelos alunos.

Transformar a cultura escolar pressupõe compreender que

Além das questões de natureza política e social, também as de natureza epistemológica e didática fazem parte do processo de desenvolvimento curricular. Dentre elas destacam-se: que Matemática deve ser ensinada às crianças e jovens de hoje e com que finalidade? Como teorias didáticas e metodológicas devem ser 
incorporadas ao debate curricular, sem que sejam distorcidas e tragam mais prejuízos do que ganhos para a aprendizagem dos alunos? (PIRES, 2005, p. 26).

Um aspecto da contribuição de Pires me interessa mais diretamente nesta discussão, constituindo o objeto de investigação: quais são as correntes psicológicas que nortearam as tentativas de reorganização curricular em Matemática nas últimas décadas e como elas influenciaram, ou não, o trabalho didático-pedagógico nesta área do conhecimento?

Busco respostas para essa questão analisando documentos curriculares do estado de São Paulo, além dos Parâmetros Curriculares Nacionais e da Base Nacional Comum Curricular, BNCC, referentes ao ensino de Matemática.

Considero que é a partir da própria experiência sociocultural dos sujeitos de aprendizagem que se facilita a apropriação do conhecimento matemático. Impõe-se, então, a necessidade de uma metodologia apoiada na valorização do raciocínio próprio de forma a se conduzir a proposições mais abstratas e à utilização do raciocínio formal, lógico e dedutivo típico da Matemática. Tendo como horizonte ultrapassar os limites das meras representações simbólicas, o trabalho pedagógico em Matemática deve contribuir para o desenvolvimento de habilidades de raciocínio, processo interposto inicialmente pela linguagem oral e que, com o decorrer da escolarização, incorpora práticas, textos, contextos e representações mais elaborados.

Durante muito tempo se acreditou que o bom professor de Matemática era aquele que dominava o conteúdo, ou seja, o objeto do professor seria o conteúdo que ministra. A despeito da importância dessa tese, nas quatro últimas décadas a busca por melhoria nos indicadores de qualidade na aprendizagem de forma geral e da Matemática, em especial, dado o seu uso social, obriga o aparato escolar a buscar uma abordagem compreensiva da Matemática, apropriando-se das diferentes concepções tanto da Matemática 
científica quanto da escolarizada, reconhecendo o paradigma ao qual se filiam:

Além disso, deve ser considerado que existem diferentes tipos de aprendizagem e que nem todas as coisas são aprendidas da mesma maneira. Decorar um poema é diferente de aprender um algoritmo e ser capaz de aplicar esse algoritmo a problemas semelhantes, transferindo assim a aprendizagem de uma situação para outra. (BRITO, 2011, p. 3).

Progressivamente, o professorado necessita reconhecer que a concepção platônica de Matemática, pautada por repetição e memorização e demonstrações quase nunca compreendidas, ou a aplicação inadequada do modelo formal euclidiano, ainda muito presente nos materiais didáticos, reforçam posturas pedagógicas que pouco contribuem para a produção de uma prática pedagógica capaz de desenvolver a autonomia de pensamento e de linguagem do aluno.

\section{Percurso metodológico}

Analiso as influências das teorias de aprendizagem a partir de pesquisa bibliográfica e de análise documental sobre as principais reformas curriculares pós-70. Efetuo a análise sobre a documentação das reformas curriculares no contexto do estado de São Paulo e de duas ações orientadoras de reorganização curricular elaboradas em âmbito nacional, ainda que sob a forma de definição de princípios para a base legal, teórica e metodológica a ser explorada pelas secretarias de educação na formulação dos programas de ensino de Matemática.

Em suma, desenvolvo uma análise crítica dos documentos que fundamentam o processo de elaboração e de implementação das reorganizações curriculares com base nos seguintes princípios:

a) fundamentação teórica da proposta, em particular, do procedimento 
metodológico que recomenda;

b) a concepção de Matemática que a escola deve veicular e aquela que parece emergir do discurso pedagógico aos quais os documentos se filiam.

\section{Fundamentação teórica e análise do problema de pesquisa}

A partir deste tópico, enuncio as bases teóricas sobre a qual analiso a questão central de pesquisa e seus invariantes, iniciando por uma breve discussão sobre os antecedentes históricos da questão e avançando para a análise dos fundamentos teóricos das reformas a partir dos anos de 1960.

$\mathrm{O}$ objeto de estudo que delineei tem seus antecedentes históricos no período imediatamente posterior à Segunda Guerra Mundial no qual se constata, praticamente no mundo todo, uma profusão de propostas de reformulação dos programas de ensino de Matemática. De um lado, a percepção da Matemática como conhecimento fundamental para consolidação do desenvolvimento tecnológico compreendido como imperativo para a recuperação dos países devastados pelo conflito. De outro, a preocupação das grandes potências com a consolidação e melhoria do processo científico para a manutenção da hegemonia, mas todas elas reconhecendo a necessidade de melhoria de seu ensino face ao desempenho insatisfatório dos alunos.

Mostra-se evidente neste período histórico que a Matemática fundamenta a sustentação de todo o pensamento científico e é base para o desenvolvimento tecnológico, sendo que o imperialismo busca a proliferação dessas ideias no contexto dos países periféricos. No Brasil, essa influência é conhecida e se concretiza nos acordos entre o Ministério da Educação e Cultura (MEC) e a United States Agency for International Development (USAID), a Agência dos Estados Unidos para o Desenvolvimento Internacional, constituindo os chamados "Acordos MEC/USAID”.

Nota-se, então, no período do pós-guerra, uma tentativa de modernização dos currículos de Matemática por se considerar a existência de defasagem entre a pesquisa e o ensino, além dos exageros na apresentação 
formal, considerada distante dos modos de pensar dos alunos desde os anos iniciais da escolarização. Vê-se que o problema não é recente.

Criticava-se abertamente a opção pelo método axiomático, pautado pela ênfase no modelo formal euclidiano, nos postulados e nos teoremas cujas demonstrações eram consideradas estéreis e, via de regra, não compreendida pelos estudantes. A esse desejo de transformação das práticas pedagógicas em Matemática se logrou denominar de Matemática Moderna, movimento iniciado nos EUA e na Europa no final da década de 1.950 e que chega ao Brasil, de certa forma tardiamente, em meados da década de 1.960.

Importante destacar que o modelo axiomático enfatiza a Matemática pensada do ponto de vista do matemático que visa à constituição de um modelo formal voltado à economia de pensamento, isto é, vê a Matemática por dentro. Além disso, a evolução das ideias matemáticas, na forma como geralmente é apresentada aos alunos, pode conduzi-los a pensar que o conhecimento novo jamais supera ou contradiz o anterior, fato que permite a falsa percepção de uma aparente regularidade.

Quando do desenvolvimento na dimensão escrita do fato matemático, nota-se, de início, um momento caracterizado pela elaboração criativa da nova ideia e, a posteriori, uma etapa de formalização voltada à observação do rigor metodológico; na escola, raramente se permite às crianças condições favoráveis para a percepção desses momentos de natureza distintas, ainda que o produto final da criação e da redação se revele por aprimoramentos sucessivos.

Daí, a ideia de fustigar o processo de ensino de Matemática em função da reprodução do modelo hipotético-dedutivo do tipo "se hipótese, então tese" revelou-se, como mostraremos no tópico a seguir, um equívoco conceitual haja vista que o problema pedagógico, de fato, era outro: não se considerar na formação dos alunos as experiências e vivências que traziam para a escola, produzindo sentidos e negociando significados matemáticos, de modo a superar a concepção internalista dos programas de ensino da disciplina. Uma coisa era a organização da Matemática como ciência, o que não permitia 
pensar a desconsideração do modelo axiomático; outra era a reprodução desse modelo formal mediante repetição e memorização, efetivamente um obstáculo didático a ser superado.

Como resposta às críticas ao ensino de Matemática, tido como de orientação clássica, o movimento de renovação dos programas de ensino da disciplina entende que é chegada a hora de se considerar na organização curricular as teses do movimento da Matemática Moderna, o que tem por base inicial a região sudeste do país, especialmente o estado de São Paulo, mas que rapidamente se expande por todo o país dada a condição de grande centro produtor de livros didáticos deste estado.

\section{Guias curriculares para o ensino de $1^{\circ}$ grau: sintonia com a matemática moderna?}

O documento introdutório dos Guias Curriculares Propostos para as Matérias do Núcleo Comum do Ensino de $1^{\circ}$ Grau do estado de São Paulo se inicia discutindo algumas contradições no debate sobre o ensino dessa disciplina que se revelam em duas questões apresentadas:

$1^{\text {a) }}$ Qual método deve ser utilizado: axiomático ou intuitivo? 2a) Qual orientação a ser dada: clássica ou moderna? A decisão não é fácil. Por esse motivo, procuramos elaborar um programa que dentro de certos limites, permita a opção por qualquer das soluções que se apresentem. Achamos, no entanto, que seria de bom alvitre apresentar nossa opinião particular sobre essas questões. (SÃO PAULO, 1975, p. 171).

Primeiramente, se a reforma era um enfrentamento com a orientação excessivamente centrada na componente simbólica, conceitual e formalística, até então vigente, a Matemática como coisa pronta, como seria possível a opção por qualquer das soluções que se apresentassem nos termos indicados?

De fato, o problema era conceitual porque na sequência o documento 
esclarece que um tratamento axiomático não seria compatível com o ensino de $1^{\circ}$ grau, mas que isso não significaria um abandono do rigor que caracteriza o raciocínio matemático, que é defendido na totalidade do desenvolvimento do programa de ensino de Matemática. Isso também não resolveria o problema pedagógico em voga haja vista que, ainda segundo os Guias Curriculares,

[...] devemos procurar obter os documentos com base nas atividades do aluno, na manipulação de instrumentos e materiais didáticos adequados, em situações tão próximas do concreto e da experiência do aluno quanto seja possível. A passagem do concreto ao abstrato deve ser feita gradativa e cuidadosamente, etapa por etapa, atendendo ao nível de amadurecimento do aluno. (SÃO PAULO, 1975, p. 171).

De início, destaque-se as bases psicológicas reconhecidamente empiricistas na fundamentação do Guia Curricular. Por outro lado, embora afirmasse que Matemática não deveria ter adjetivos, nem clássica e nem moderna, mas simplesmente ser Matemática, ao citar Piaget o documento se revelava novamente contraditório porquanto acreditava que o movimento era necessariamente de ascensão do concreto ao abstrato, com o concreto, neste caso, tomado claramente como sinônimo de manipulável, e que era possível combater a orientação clássica, excessivamente formalista, no ensino de Matemática, com base nas teses da Matemática Moderna.

É oportuna uma citação do próprio Piaget acerca da proximidade de suas ideias com o referencial da Matemática Moderna, a qual não pode ser negligenciada na discussão acerca da influência das teorias de aprendizagem que sustentam tanto o Guia, quanto a proposição curricular subsequente levada a termo a partir de 1980 no estado de São Paulo:

Todos conhecem as idéias centrais da escola Bourbaki, que põe na base do edifício matemático três grandes estruturas-mãe 
(algébricas, de ordem, topológicas), de que as inúmeras estruturas particulares derivam por diferenças e combinações; ora, os trabalhos de Genebra conseguiram mostrar que estas três estruturas-mãe correspondem sob formas concretas e limitadas às três estruturas operatórias elementares que se encontram na criança desde a formação das primeiras operações lógicomatemáticas. (PIAGET, 1973, p. 120).

Escola Bourbaki era o pseudônimo de um grupo de matemáticos eminentes, como Jean Diedounné e Adrien Douady, por exemplos. Fundada em 1.935, notabilizou-se historicamente pela apresentação rigorosa e formalística das ideias matemáticas, de abordagem abstrata e pouco usual até aquele momento histórico.

Vê-se, então, que predomina, seja no pensamento piagetiano, seja na Matemática Moderna, a visão estruturalista que se revela na linguagem simbólica da teoria dos conjuntos. Por óbvio, o discurso da Matemática Moderna é formalista e euclidiano. A citação a seguir ilustra bem a síntese do movimento renovador quando considera que

O objetivo da matemática moderna de tratar simultaneamente várias estruturas determina sua forma. Ela é necessariamente axiomática, dedutiva e abstrata. Ela define um tipo de estrutura, um corpo, por exemplo, como um conjunto de elementos e de relações que satisfazem certos axiomas. Da mesma maneira que a geometria euclidiana, a matemática moderna deduz teoremas a partir de axiomas. (ADLER, 1970, p. 63).

Por essas formulações é que se observam na análise dos livros didáticos de Matemática da época, todos eles carimbados com a expressão "De Acordo com os Guias Curriculares do Estado de São Paulo”, a excessiva exploração das relações de pertinência (relações pertence ou não pertence entre elemento e conjunto) e inclusão hierárquica (relações contém ou não contém e contido ou não contido entre subconjunto e conjunto), base do discurso matemático 
centrado na linguagem da teoria dos conjuntos e na abordagem formal da ciência matemática, influência que advém do uso do modelo formal euclidiano, equivocadamente tomado como modelo de ensino.

Resulta dessa discussão que não é coerente fustigar a Matemática clássica com as teses da Matemática Moderna porque ambas são estruturalistas conforme registram Piaget e Adler ao se reportarem às estruturas-mãe da escola bourbakista e à dedução de teoremas, a partir de axiomas, respectivamente.

Também não é coerente questionar a Matemática Moderna a partir das teses piagetianas porque ela conflui nitidamente para o construtivismo piagetiano. Além disso, curiosamente, as principais críticas que o professorado fazia no início dos anos de 1980 eram quanto à orientação behaviorista dos Guias e a sua marca distintiva de prescrição curricular. Vêse, então, que as contradições da própria reforma e a falta de envolvimento dos docentes na elaboração e na implementação prática dos Guias, de certo modo, os inviabilizaram.

Em que pese a tentativa de modernização dos programas de ensino de Matemática predomina, seja no discurso dúbio dos Guias, seja na conduta pedagógica da maioria das salas de aulas, a perspectiva de ensino por transmissão de conhecimento via associação de modelos matemáticos prontos a serem repetidos à exaustão, fortemente influenciada pelas teorias behavioristas da aprendizagem. Ensinar e aprender Matemática devem constituir processos indissociáveis haja vista que:

Sabe-se que a típica aula de matemática em nível de primeiro, segundo ou terceiro graus ainda é uma aula expositiva, em que o professor passa para o quadro negro aquilo que ele julgar importante. $\mathrm{O}$ aluno, por sua vez, copia da lousa para o seu caderno e em seguida procura fazer exercícios de aplicação, que nada mais são do que uma repetição na aplicação de um modelo de solução apresentado pelo professor. Essa prática revela a concepção de que é possível aprender matemática através de um processo de 
transmissão de conhecimento. Mais ainda, de que a resolução de problemas reduz-se a procedimentos determinados pelo professor. (D’AMBROSIO, 1989, p. 15).

Uma observação atenta do cotidiano da maioria das salas de aula de Matemática revelará que esse quadro pouco se alterou. Como se sabe, prevalece nessa lógica instrucional de organizar o ensino o papel passivo do aluno, assumindo o professor o controle absoluto da aula, cabendo a ele a definição do que ensinar, do tempo que necessita para fazê-lo e a definição específica dos objetivos que pretende alcançar. O conhecimento pedagógico da época não foi suficiente para perceber que, dada a heterogeneidade sociocultural da clientela que ganhava acesso à escola, seria impossível ensinar tudo a todos, ao mesmo tempo, e, com os mesmos recursos didáticos. O resultado foi o recrudescimento da seletividade da escola que, a partir desse momento, de forma progressiva, começa a superar a negação da vaga no ensino de $1^{\circ}$ grau, mas não garante as condições pedagógicas necessárias para a permanência dos alunos com êxito na escola.

Desse modo, as diretrizes curriculares para o Ensino de Matemática, configuradas nos Guias Curriculares, não conseguiram se firmar como bom encaminhamento para esta área do conhecimento, mas o fato é que se tornaram hegemônicas em praticamente todo o país pela grande profusão de textos didáticos produzidos no estado de São Paulo.

\section{Democratização do ensino e currículo como ação compartilhada.}

Com base no ideário da redemocratização da sociedade brasileira, na crítica à orientação comportamentalista dos Guias Curriculares e de seus Subsídios, inicia-se a partir de 1983 uma série de reformas no sistema educacional, especialmente nos Estados nos quais os políticos eleitos se filiavam ao movimento.

Além disso, coloca-se em evidência a ideia de que o desenvolvimento de 
currículos de Matemática no Brasil apresentava tendência de prescrição e normatização, prevalecendo em determinadas reformas a organização lógica e em outras a evolução histórica das ideias matemáticas na organização do ensino, pouco se considerando os aspectos socioculturais envolvidos na atividade matemática conforme se pode constatar com estudos como o desenvolvido por Pietropaolo (1999) e Imenes (1989).

Solidificava-se, desse modo, a compreensão de que era chegada a hora. de maior envolvimento dos professores no delineamento dos currículos, opondo-se à tradição prescritiva da organização curricular uma perspectiva de gestão de currículos que tem na ação compartilhada o seu pressuposto básico. No caso do estado de São Paulo, o calendário escolar passa a abrir espaço para discussões sobre as propostas curriculares que começavam em cada escola, eram aprofundadas em nível das chamadas delegacias de ensino e avançavam para o fechamento do debate em processos centralizados na Coordenadoria de Estudos e Normas Pedagógicas, a CENP, ou na Fundação para o Desenvolvimento da Educação, a FDE, com apoio de assessores docentes das universidades públicas.

No plano pedagógico, considerava-se que a escola era excessivamente seletiva e as propostas curriculares em voga eram, em geral, teóricas, complexas e genéricas, não oferecendo os instrumentos necessários à sua aplicação prática pelos professores e pouco contribuindo para o pleno desenvolvimento cognitivo dos alunos. Some-se a essa discussão, o baixo rendimento dos alunos em uma área do conhecimento que se destaca pelo lúdico e pela beleza formal e a ênfase exagerada no simbolismo lógico-formal, o que oculta o processo de construção do conhecimento matemático, tornandoo a-histórico e atemporal.

Recrudesciam, então, as críticas ao processo de difusão do conhecimento matemático como uma ciência fechada em si mesma, rompendo com os vínculos que dão sentido e significação às ideias veiculadas, o desenvolvimento de programas de ensino isolados no currículo, sem integração dos temas entre si e principalmente com as outras áreas do 
conhecimento.

Essas críticas eram bem fundamentadas à época. Niss (1981) considerava que a educação matemática reflete as necessidades da sociedade como um todo e como tal se expõe aos interesses políticos, ideológicos e econômicos. Por sua vez, Imenes (1989) alertava que a organização das ideias matemáticas pelo critério da precedência lógica eliminava todos os demais aspectos psicológicos, culturais e socioeconômicos envolvidos na criação matemática.

A Proposta Curricular para o Ensino de Matemática no estado de São Paulo revelava traços teóricos das metodologias voltadas à aprendizagem ativa, priorizando explorações e descobertas efetivas com vistas à efetiva compreensão. Havia a clareza de que isso exigiria respeitar os ritmos de desenvolvimento cognitivo dos alunos bem como a integração dos temas da Matemática em um contexto claramente cognitivo-construtivista.

Uma célebre citação da obra de Bruner (1974, p. 8) define bem o que se pretendia com a reforma: “[....] dominar as ideias básicas, usá-las eficientemente, exige constante aprofundamento da compreensão que delas se tem, o que se pode conseguir aprendendo-se a utilizá-las de formas progressivamente mais complexas."

Era, ao mesmo tempo, a crítica à tergiversação entre a Matemática clássica e a Matemática Moderna constatada nos Guias de 1.975 e a opção clara pelo que se denominava de "currículo em espiral" em oposição à opção do documento anterior pelo "currículo em escada" cuja organização era considerada linearizada, com os temas sendo tratados de forma estanque.

Desse modo, opondo-se a uma perspectiva pedagógica marcada ao nível psicológico pelas correntes behavioristas a Proposta Curricular paulista bem como todas as demais tentativas de renovação dos programas de ensino em todo o país recebe fortemente as influências do ideário neopiagetiano. Outro fundamento importante da reforma, talvez o mais inovador, porque contemplava a questão do desenvolvimento cognitivo e a heterogeneidade da clientela das camadas populares que chegava à escola, especialmente ao que 
hoje corresponde ao segundo segmento do ensino fundamental, foi a organização do $1^{\mathrm{o}}$ grau em ciclos básico ( $1^{\mathrm{a}} \mathrm{e} 2^{\mathrm{a}}$ séries), intermediário $\left(3^{\mathrm{a}}, 4^{\mathrm{a}} \mathrm{e}\right.$ $5^{\mathrm{a}}$ séries) e final ( $6^{\mathrm{a}}, 7^{\mathrm{a}}$ e $8^{\mathrm{a}}$ séries).

Essa proposta dos ciclos visava enfrentar o problema do desenvolvimento dos alunos e a seletividade do sistema, mas não vingou por conta da resistência do professorado. Observou-se que essa resistência era mais acentuada em aspectos da reforma que exigiam maior reflexão e reformulação conceitual sobre o trabalho pedagógico. Para evitar o confronto com os docentes, a gestão da reforma recuou e manteve apenas o Ciclo Básico, sendo que as crianças nesse sistema somente poderiam ser reprovadas ao final da $2^{\mathrm{a}}$ série.

Claramente se nota nas reformas curriculares pós-1982 a busca de enfrentamento ao tecnicismo pedagógico inerente aos Guias Curriculares e ao movimento da Matemática Moderna e a tentativa de envolvimento dos professores na promoção de aprendizagem pela descoberta mediante o desenvolvimento de atividades exploratórias e de uma atitude investigativa por parte dos alunos. Se essa postura situa o foco da aprendizagem no aluno, ainda se percebe a ênfase centrada na estrutura dos temas da Matemática e pouco significado é atribuído ao contexto da aprendizagem. Mas essa necessidade parecia clara ao menos para alguns membros da equipe técnicopedagógica envolvida na elaboração da Proposta ao discutir o lugar da Matemática no currículo:

Parafraseando Vygotsky, são como os átomos de hidrogênio e oxigênio em uma molécula de água: não é possível compreender as propriedades da água através da consideração isolada de um ou de outro elemento. A água apaga o fogo enquanto o oxigênio alimentao e o hidrogênio arde. A molécula de água representa a unidade indispensável que se deve considerar para a análise das propriedades da água, de suas funções. (SÃO PAULO, 1986, p. 9).

Essa citação revela que na equipe técnico-pedagógica que elaborou a 
Proposta paulista havia dissenso quanto à fundamentação teórica. No entanto, há de se registrar, além da influência piagetiana, que as reformas curriculares a partir dos anos de 1.990 recebem influência considerável da Teoria da Assimilação de AUSUBEL e colaboradores (1980), enfatizando o modo como o conhecimento a ser aprendido é tornado disponível ao aluno, se por recepção ou por descoberta, e o modo como os alunos incorporam essa informação nas suas estruturas cognitivas, se de forma mecânica ou significativa. Nota-se nos Parâmetros Curriculares Nacionais e no Programa SP Faz Escola a ênfase no currículo em rede de significados e a busca de um processo pedagógico pautado no ensino por pesquisa.

Segundo a Teoria da Assimilação, são quatro os tipos de aprendizagem: por recepção mecânica, por recepção significativa, por descoberta mecânica e por descoberta significativa. Destaca que em uma fase inicial a informação torna-se ao alcance do sujeito em aprendizagem por recepção e/ou por descoberta. Em segundo momento, se o aluno tenta reter a informação nova, relacionando-a ao que já sabe, ocorre aprendizagem significativa, mas se tenta simplesmente memorizar a informação nova, ocorre aprendizagem mecânica.

Vê-se que o período agora em análise é marcado por uma efervescência teórica que se estabelece no debate acadêmico, mas é pouco incorporada nas práticas pedagógicas da educação básica. Há de se destacar como resultados desse debate as concepções de aprendizagem verbal significativa, a adoção de modelos didáticos com base em mapas conceituais, a organização curricular em rede e a perspectiva de ensino por mudança conceitual que não visa apenas à aquisição de novos conhecimentos pelos alunos, mas impõe a necessidade da reorganização conceitual. Observe-se a postura teórica sobre a origem do conhecimento e a aprendizagem:

Como um incentivador da aprendizagem, o professor estimula a cooperação entre os alunos, tão importante quanto a própria interação adulto/criança. A confrontação daquilo que cada criança 
pensa com o que pensam seus colegas, seu professor e demais pessoas com quem convive é uma forma de aprendizagem significativa, principalmente por pressupor a necessidade de formulação de argumentos (dizendo, descrevendo, expressando) e a de comprová-los (convencendo, questionando). (BRASIL, 2000, p. 41).

Todavia, a principal característica do período pós-80 é a busca de ruptura com a tendência de prescrição curricular a favor da tendência de ação compartilhada. De fato, estudos como os desenvolvidos por Britis (2017) enfatizam a importância de se pensar o papel da atuação efetiva dos professores na consolidação do currículo real bem como da necessária aproximação entre os que pesquisam e respondem pela formação inicial e continuada de educadores com o cotidiano da sala de aula de Matemática.

Em que pese os esforços, que devem ser reconhecidos, essa tendência é abalada, de certo modo, pela elaboração dos Parâmetros Curriculares Nacionais (1998) e do Currículo Pleno do Estado de São Paulo, no âmbito do Programa SP Faz Escola (2007), que retomam a elaboração dos documentos curriculares por especialistas, para somente após a implantação discutir com os docentes os seus detalhamentos.

Por sua vez, na elaboração da Base Nacional Comum Curricular, a BNCC, (BRASIL, 2017) verificou-se uma tentativa de envolvimento dos professores na discussão sobre os princípios gerais a serem observados pelas equipes técnicas via consulta pública mediante tecnologias de informação e comunicação, mas se constata uma participação muito tímida em temos de sugestões e de contribuição dos docentes da educação básica pública, o que preocupa se considerarmos o fato de que são os profissionais que efetivam o currículo real neste nível de formação.

Novamente a participação dos especialistas em currículo se mostrou mais efetiva, mas igualmente, a ingerência de instituições voltadas ao mercado de produção de material didático configurando situação, já há algum 
tempo denunciada, na qual se constata uma luta por hegemonia de uma determinada concepção, ou seja, uma política sociocultural que busca consolidar determinados bens simbólicos e consenso para uma determinada ordem:

\begin{abstract}
No atual contexto, essa disputa tem ocorrido entre os grupos empresariais e as associações educacionais e universidades, com visível vantagem dos primeiros, desconsiderando a produção científica do país, a maioria dela financiada com verbas públicas. $\mathrm{O}$ modo como a BNCC foi elaborada destitui os direitos de aprendizagem da criança. (PASSOS \& NACARATO, 2018, p. 125).
\end{abstract}

Observa-se ao longo do documento um discurso centrado na Pedagogia das Competências, ou seja, enfatiza as competências e habilidades do aluno, o que permite pensar que consideram o pensamento matemático como uma capacidade individual do estudante e não como uma construção histórica e cultural. Por óbvio, há uma concepção teórica de aprendizagem que se revela persistente na discussão curricular desde o final dos anos de 1990.

Essa é uma marca distintiva da BNCC que se for levada a termo pelas secretarias na tradução dos princípios do documento para a elaboração dos programas de ensino de Matemática certamente reconduzirá à dimensão tecnicista do currículo, tão combatida desde o advento dos Guias Curriculares e da adesão, pouco refletida a nosso ver, às teses da Matemática Moderna na escola básica.

\title{
Bases da teoria histórico-cultural: as perspectivas para a transformação da cultura da matemática escolarizada.
}

Concordamos com Moreira \& Silva (1994) quando afirmam que o currículo não é uma área meramente técnica, que deve se preocupar apenas com questões relativas à organização do ensino, em aspectos técnicos e métodos, isto é, ele deve ser compreendido como um campo no qual se pode 
impor não apenas a cultura do grupo dominante, mas também o conteúdo dessa cultura.

$\mathrm{Na}$ perspectiva de se pensar o papel dos conteúdos de ensino, abordando-os não como fins de ensino em si mesmos, mas como instrumento para atingir fins educacionais relevantes e não meramente instrucionais, podemos caminhar no sentido de busca da consolidação da componente sociocultural da educação matemática, sem prejuízo de se pensar um processo de ensino pautado pela pesquisa.

Na percepção de Lessa \& Da Rocha Falcão (2005, p. 1),

$\mathrm{Na}$ perspectiva denominada sócio-culturalista ou sócio-histórica, Vigotski (2001) defende que o pensamento forma-se a partir de ferramentas mediacionais simbólicas. Para este autor, o processo de desenvolvimento cognitivo não segue padrões estruturais gerais de natureza biológico-adaptativa [...] Nesse sentido, o aporte simbólico proporcionado à criança por seu contexto sócio-cultural imediato (aí incluída a escola) e o desenvolvimento geral não representam dois processos independentes, mas um único processo no contexto do qual estes dois aspectos se inter-relacionam de forma complexa.

Vigotski (2007) afirma que o homem não apenas faz parte de seu meio, mas é agente criador desse meio, mantendo relações sociais com o mundo à sua volta. Tendo como base o materialismo histórico e dialético, Vigotski entendia que as transformações históricas, sociais e culturais que ocorrem ao longo da história desenvolvem e modificam a natureza humana. Ou seja, a sociedade é, ao mesmo tempo, construção histórica e produto da ação do homem, que a transforma.

Por isso, o autor e colaboradores como Davidov (1988) argumentam que a base para a teoria psicológica e pedagógica do ensino desenvolvimental é o materialismo histórico e dialético. Para ele, a principal tese dessa teoria é que tanto o ensino quanto a educação são fundamentais para o desenvolvimento 
mental do indivíduo. Afirma que a atividade de estudo é uma das principais atividades que proporciona ao aluno desenvolver seu pensamento teórico, seus conhecimentos e sua consciência.

Vygotsky (2001) aponta para três fundamentos basilares do método de investigação do processo de formação e apropriação de conceitos pelos estudantes. Em sua visão, trata-se de analisar o processo no qual ocorre o fenômeno em estudo e não o objeto em si mesmo; enfatizar a explicação e a compreensão do fenômeno abordado e não apenas sua mera descrição; e, por fim, considerar que os processos que se constituem em um longo período de desenvolvimento histórico tendem a se automatizar e escondem a aparência original. Por certo, a forma de difusão do conhecimento matemático na escola básica não se atém a esses invariantes, ao menos é o que parece indicar todas as avaliações de larga escala realizadas nos últimos anos.

Vygotsky (2006) estabeleceu, então, que a generalização configura um ato do pensamento que é semântico/conceitual e reflete a realidade de forma bastante distinta do modo como esta se apresenta nas sensações e nas percepções imediatas. Com veemência, ele defende o significado da palavra como unidade do pensamento e da linguagem, mas enfatiza que também é unidade de generalização, de comunalidade, de comunicação e de pensamento. Nessa linha de raciocínio, Vygotsky estabelece um confronto com as tendências naturalísticas e biológicas da Psicologia, mas o aspecto fundamental de sua contribuição é a formulação de uma análise genéticocausal do pensamento e da linguagem, fazendo uma distinção entre o significado verbal e as outras representações.

Como principal desdobramento dessa formulação de natureza semiótica, a criança somente pode se apropriar de conhecimentos e habilidades, na perspectiva da atividade de estudo, se ela tem uma necessidade interna e motivação para a apropriação do conceito em voga:

Devemos observar que, na ciência lógica, os conhecimentos sobre a interligação entre aspectos essenciais gerais e aspectos particulares 
são chamados de conhecimento teórico. A necessidade da criança no processo de ensino é, precisamente, sua aspiração de obter conhecimento sobre aspectos gerais de um objeto, ou seja, o conhecimento teórico sobre algo por meio da experimentação e exploração com o objeto. Estas transformações e experimentações com o objeto envolvem, necessariamente, elementos criativos. Quando o professor cria sistematicamente na sala de aula as condições que exijam dos alunos a obtenção de conhecimentos sobre o objeto por meio da experimentação com este, as crianças se deparam com tarefas que exigem delas a atividade de estudo (DAVIDOV, 1999, p. 2, grifos do autor).

Nesse sentido, conforme Vygotsky (2007, p. 36), a participação em atividades socioculturais mediatiza o desenvolvimento do conhecimento, sendo que por meio das interações com os outros o educando se envolve nas práticas sociais, internalizando os processos socioculturais externos como uma parte orgânica da prática. Ou seja, a aprendizagem se dá primeiro no plano da experiência social mediada por sistemas simbólicos culturais, especialmente a linguagem, e depois no plano da cognição individual.

Em síntese, cumpre estabelecer que no processo de aprendizagem os sujeitos se apropriam dos processos interativos para estender os conhecimentos ao envolvimento na interação social no espaço intersubjetivo, parte constitutiva da apreensão intersubjetiva, conforme se consigna na teoria histórico-cultural.

Daí que, questionar os cânones de uma cultura de Matemática escolarizada que se revela em uma visão estática da realidade envolve o propósito de considerar os caracteres dinâmico, contraditório, histórico e dialético dos fenômenos educativos. O que se evidencia na escola e na sociedade hoje nada mais é do que uma síntese do processo histórico em transformação. É fato que ao refletir e sistematizar a sua prática de ensino, os professores produzem e renovam saberes. $\mathrm{O}$ ato de ensinar exige abarcar a totalidade do fenômeno educativo, sendo que ao ensinar o docente tenta 
contemplar as múltiplas dimensões e perspectivas de sua atividade docente, o que envolve valores e posturas frente à sociedade e ao que compreende como ação de educar. Ou seja,
Durante o processo de aprendizagem, é preciso que o professor tenha muito claro todo o conjunto de ações de estudo, tanto gerais como específicos, em conformidade com a assimilação das crianças, de uns e outros conceitos ou modos de ação, para resolverem as tarefas de alguns tópicos da matéria. Há que formar, especialmente e com insistência nos pequenos escolares, o sistema de ações de estudo indispensáveis. Sem essas ações, a assimilação do material se efetuará às margens da Atividade de Estudo. Isso significa que a aprendizagem se fez formalmente, com a mera descrição verbal dos conceitos ou modos de ação de resolver problemas (DAVIDOV, 2019, p. 185, grifos no original).

Essa forma de conceber o ensino e a educação, com consequências inquestionáveis para a renovação dos programas de ensino, ainda não foi considerada de forma significativa na organização curricular no Brasil.

Essa preocupação se justifica porque se nota, em geral, certo descontentamento na análise de indicadores sobre a situação dos processos de ensino e aprendizagem da Matemática. Os estudantes, apesar de manterem uma boa relação com certos conteúdos matemáticos antes da escolarização, mesmo sem assim reconhecê-los, mostram na escola certa resistência à disciplina, fruto de crenças e convenções sociais e culturais, que os impedem de reconhecer a Matemática como parte integrante de suas vidas.

No que tange aos professores, a formação recebida, por vezes, não possibilita uma abordagem segura dos conteúdos de modo que muitos se abrigam na pretensa segurança dos modelos tradicionais pautados por procedimentos automatizantes que não dão conta de instigar nos alunos a vontade de aprender.

Claramente marcados pela concepção internalista de organização dos 
programas de ensino, concebendo o processo de ensino da forma como o matemático percebe a Matemática, um dos grandes desafios para a formação de professores revela-se na necessidade de atendimento das especificidades do trabalho educativo relativamente às diferentes etapas da vida dos estudantes, superando a visão segmentada do desenvolvimento e da aprendizagem.

O problema exige considerar, um pouco mais, no desenvolvimento dos programas de ensino de Matemática os artefatos socioculturais que se revelam nas práticas que as crianças desenvolvem diuturnamente antes de chegarem à escola, seja no jogo, nas brincadeiras ou em inúmeras práticas sociais que permitiriam considerar a concepção externalista de organização do currículo escolar.

Nesse corolário situam-se os limites e as necessidades de transformação da cultura da matemática escolarizada.

\section{Considerações a guisa de conclusão}

Historicamente, posturas teórico-metodológicas fortemente enraizadas no cotidiano da escola de educação básica conduziram o trabalho pedagógico em Matemática no sentido de reprodução de modelos que embora priorizassem o rigor no trato científico desta área de conhecimento, pouco contribuiram para o pleno desenvolvimento intelectual dos estudantes.

Progressivamente, esse problema vem sendo abordado no contexto das reformas curriculares com vistas ao desenvolvimento de um programa de ensino pautado pela produção de sentidos de aprendizagem e de negociação de significados em Matemática. Esse trabalho não pode prescindir de envolvimento do professorado em um processo de ação compartilhada para a elaboração dos programas de ensino de Matemática, sendo que a Psicologia e a Didática podem e devem exercer papéis fundamentais para melhor encaminhamento das práticas escolares nesta área do conhecimento.

Por certo, o conhecimento produzido já logrou estabelecer que o fazer 
pedagógico é um processo contínuo de ação-reflexão-ação e que em função da multiplicidade dos fatores que interferem nos processos de ensino e de aprendizagem, nem a Psicologia, nem a Didática, per se, são capazes de fornecer respostas definitivas para as situações cotidianas de sala de aula enquanto prevalecer a perspectiva internalista de organização dos programas de ensino de Matemática. Mas há muitos caminhos que podem ser trilhados e um dos mais promissores é o envolvimento do alunado em um trabalho interativo de investigação, onde a cada reflexão sobre determinada ação buscam-se parâmetros para a formulação das ações futuras.

Trata-se, então, de centrar a ênfase na apreensão das ideias matemáticas, na justificativa e no significado dessas ideias, caminho pedagógico oposto à preocupação com o desenvolvimento de uma linguagem carregada nos simbolismos e na aplicação, sem compreensão, de esquemas e algoritmos. Impõe-se pensar a constituição do pensamento teórico.

Por fim, trata-se de inserir o professor no debate sobre currículo, efetivamente, visando transformar a cultura escolar. É um movimento de continuidade, no sentido de busca de envolvimento dos docentes na elaboração dos currículos; e de ruptura, com os ditames de uma perspectiva de desenvolvimento centrada nas bases naturalísticas e biológicas da Psicologia.

\section{Referências}

ADLER, I. Matemática e Desenvolvimento Mental. São Paulo, Cultrix, 1970.

AUSUBEL, D.; NOVAK, J. D. \& HANESIAN, H. Psicologia Educacional. Rio de Janeiro, Interamericana, 1980.

BRASIL, REPÚBLICA FEDERATIVA. Parâmetros Curriculares Nacionais: Matemática. Brasília, Ministério da Educação e Cultura, 2000.

BRASIL, REPÚBLICA FEDERATIVA. Base Nacional Comum Curricular. Brasília, Ministério da Educação e Cultura, 2017.

BRITIS, K. G. A trajetória de uma educadora matemática paulista como curriculista e formadora de professores de Matemática. 2017. Dissertação (Mestrado Profissional em Ensino de Ciências e Matemática). 167 p. Universidade Cruzeiro do Sul, São Paulo. 
BRITO, M. R. F. de. Contribuições da Psicologia Educacional à Educação Matemática. In: BRITO, M. R. F. de (org.). Psicologia da Educação Matemática: Teoria e Pesquisa. Florianópolis, Editora Insular, 2001, p. 49-84.

BRITO, M. R. F. Psicologia da Educação Matemática: um ponto de vista. Educar em Revista. Dossiê: Psicologia da Educação Matemática. Curitiba, 2011.

BRUM, W. P. Crise no Ensino de Matemática: amplificadores que potenciam o fracasso da aprendizagem. São Paulo, Clube dos Autores, 2013.

BRUNER, J. O processo da educação. São Paulo, Nacional, 1974.

D’AMBROSIO. B. S. Como ensinar Matemática hoje? Temas e Debates. SBEM, Ano II, n. 2. Brasília, 1.989, p. 15-19.

DAVIDOV, V. V. Problemas do ensino desenvolvimental: a experiência da pesquisa teórica e experimental na psicologia. Tradução de José Carlos Libâneo e Raquel Aparecida Marra da Madeira Freitas. [1988]. Disponível em: $<$ http://professor.ucg.br/SiteDocente/admin/arquivosUpload/5146/material/Davydov >. Acesso em 21 de nov. 2019.

DAVIDOV, V. V. O que é a Atividade de Estudo? Revista Escola Inicial, n 7, 1.999. Tradução do russo por Ermelinda Prestes, revista por José Carlos Libâneo em 2.013.

DAVIDOV, V. V. Desenvolvimento Psíquico da Criança. In: PUENTES, R. V; CARDOSO, C. G. C. \& AMORIM, P. A. P. (orgs.). Teoria da Atividade de Estudo: Contribuições de D. B. Elkonin, V. V. Davidov e V. V. Repkin - Livro I. Curitiba (PR), Editora CRV, 2.019. Coedição: Uberlândia (MG), EDUFU, 2.019, p. 175-190.

IMENES, L. M. Um estudo sobre o fracasso do ensino e da aprendizagem da Matemática. Dissertação de Mestrado. Rio Claro, UNESP, 1.989.

LESSA, M. M. L. \& DA ROCHA FALCÃO, J. T. Pensamento e linguagem: uma discussão no campo da Psicologia da Educação Matemática. Psicologia: Reflexão e Crítica, vol. 18, n. 3, Porto Alegre, set/dez. 2005.

MOREIRA, A. F. B \& SILVA, T. T. (orgs.). Currículo, Cultura e Sociedade. São Paulo, Cortez, 1994.

NISS, M. Metas como reflejos de las necessidades de la sociedad. Estúdios en Educación Matemática. UNESCO, (2), 1981.

PASSOS, C. L. B. \& NACARATO, A. M. N. Trajetória e Perspectivas Para o Ensino de Matemática nos Anos Iniciais. Estudos Avançados, 32 (94), 2018.

PIAGET, J. A Psicologia. Lisboa, Bertrand, 1973.

PIETROPAOLO, R. C. Parâmetros Curriculares Nacionais: uma análise dos Pareceres. 1999. Dissertação (Mestrado em Educação Matemática). 178 p. Pontifícia 
Universidade Católica, São Paulo.

PIRES, C. M. C. Currículos de Matemática: para onde se orientam? Revista de Educação da PUC-Campinas. Campinas, 2005, n.18, p. 25-34.

SÃO PAULO (ESTADO). Secretaria de Estado da Educação. Guias Curriculares para o Ensino de $1^{\circ}$ Grau. São Paulo, SEE, 1975.

SÃO PAULO (ESTADO). Secretaria de Estado da Educação. Proposta Curricular para o Ensino de Matemática no $1^{\circ}$ Grau. São Paulo, SEE, 1986.

SÃO PAULO (ESTADO). Secretaria de Estado da Educação. Programa São Paulo Faz Escola. São Paulo, SEE, 2007.

SCHLIEMANN, A. D.; CARRAHER, D. W.; SPINILLO, A. G.; MEIRA, L.L. \& FALCÃO, J. T. P. R. Estudos em Psicologia da Educação Matemática. Recife, Editora Universitária da UFPE, 2003.

VYGOTSKY, L. S. A Construção do Pensamento e da Linguagem. São Paulo, Martins Fontes, 2001.

VYGOTSKY, L. S. A formação social da mente: o desenvolvimento dos processos psicológicos superiores. 7. ed. São Paulo: Martins Fontes, 2007.

VYGOTSKY, L. S. Aprendizagem e desenvolvimento intelectual na idade escolar. In: VIGOTSKI, L. S.; LURIA, A. R.; LEONTIEV, A. N. (Orgs.). Linguagem, desenvolvimento e aprendizagem. São Paulo: Ícone, 2006, p. 103-118.

Recebido em novembro de 2019.

Aprovado em janeiro de 2020. 